\title{
Economic viability of ultra high-performance fiber reinforced concrete in prestressed concrete wind towers to support a $5 \mathrm{MW}$ turbine
}

\author{
Viabilidade econômica do concreto de ultra-alto \\ desempenho reforçado com fibras aplicado em torres \\ eólicas de concreto protendido para sustentação de \\ uma turbina de $5 \mathrm{MW}$
}

P. V. C. N. GAMA calmon@usp.br

T. N. BITTENCOURT a tbitten@gmail.com

\begin{abstract}
The Ultra-High Performance Fiber-Reinforced Concrete is a material with remarkable mechanical properties and durability when compared to conventional and high performance concrete, which allows its use even without the reinforcement. This paper proposes the design of prestressed towers for a $5 \mathrm{MW}$ turbine, through regulatory provisions and the limit states method, with UHPFRC and the concrete class C50, comparing the differences obtained in the design by parametric analysis, giving the advantages and disadvantages of using this new type of concrete. Important considerations, simplifications and notes are made to the calculation process, as well as in obtaining the prestressing and passive longitudinal and passive transverse reinforcement, highlighting the shear strength of annular sections comparing a model proposed here with recent experimental results present in the literature, which was obtained good agreement. In the end, it is estimated a first value within the constraints here made to ensure the economic viability of the use of UHPFRC in a $100 \mathrm{~m}$ prestressed wind tower with a $5 \mathrm{MW}$ turbine.
\end{abstract}

Keywords: Ultra-high performance fiber-reinforced concrete; UHPFRC; prestressed wind towers; shear strength; design.

\section{Resumo}

O Concreto de Ultra-Alto Desempenho Reforçado com Fibras (CUADRF) é um material com notáveis características mecânicas e de durabilidade ao comparar-se com concretos convencionais e até de alto desempenho, o que permite seu emprego mesmo sem a utilização de armadura. O presente artigo propõe o dimensionamento de torres protendidas destinadas à sustentação de turbinas de 5 MW, através de disposições normativas e do método dos estados limites, com o emprego de CUADRF e a classe de concreto C50, comparando-se as diferenças obtidas no dimensionamento por meio de análise paramétrica, atribuindo vantagens e desvantagens no uso deste novo tipo de concreto. Importantes considerações, simplificações e apontamentos são feitos para o processo de cálculo, assim como na obtenção das armaduras ativa e passiva longitudinal e passiva transversal, colocando em evidência a resistência ao esforço cortante das seções anulares ao comparar um modelo aqui proposto com recentes resultados experimentais presentes na literatura, dos quais se obtém boa concordância. Ao final, estima-se um primeiro valor dentro das restrições aqui feitas para que se assegure a viabilidade econômica no uso do CUADRF em uma torre eólica protendida com $100 \mathrm{~m}$ de altura e turbina de $5 \mathrm{MW}$.

Palavras-chave: Concreto de ultra-alto desempenho reforçado com fibras; CUADRF; torres eólicas protendidas; resistência ao esforço cortante; dimensionamento.

Universidade de São Paulo, Escola Politécnica, Departamento de Engenharia de Estruturas e Geotécnica, São Paulo - SP, Brasil. 


\section{Introduction}

The better use of the energy contained in wind occurs with greater heights, since the wind is mostly stronger and less turbulent with greater height. Thus, changes in wind turbines with increasingly greater capacity for power generation, also has been accompanied by an increase in the dimensions of components, such as the rotor, the nacelle and the tower; this has been done mainly with circular cross-section of steel or prestressed concrete, with external or internal prestressing, in situ or prefabricated (Grünberg and Göhlmann [1]).

As described by Ma e Meng [2], the concrete towers have advantages, as greater flexibility in construction and design, minimal maintenance, a better dynamic response and the best possible transport. However, in general, have been used a group I concrete strength class (La Nier [3] [1], [2], Cavalcanti et al. [4]).

The Ultra High Performance Fiber Reinforced Concrete (UHPFRC) is a material which combines high compression strength (more than $150 \mathrm{MPa}$ ) and flexural strength with a noticeable ductility and durability (AFGC [5]). While its durability is due to UHPFRC's microstructure which is much more compact and homogeneous, its ductility is guaranteed by the presence of fiber, which improves the tensile and flexural strength and allows its use in structural elements with no passive or active reinforcement. Because it is a material that requires a rigorous technology control and a higher cost of production compared to traditional materials, its use is justifiable through the design requirements, as durability of the resulting material, as well as the lightness of the structure, that could not easily be met with the use of other materials, such as the conventional concrete. For these reasons, the UHPFRC assumes a prominent position, a material with potential for use in prestressed wind towers, as seen in Jammes [6], although it is a UHPFRC wind tower not prestressed and not reinforced.

Thus, this paper investigates, through a non linear design, the use of a C50 concrete class and the use of UHPFRC in the design of prestressed wind towers, comparing the use of these materials through the total cost of each tower, proposing an initial value to which the UHPFRC becomes competitive. In this work, we used an example of a $100 \mathrm{~m}$ high tower with a $5 \mathrm{MW}$ turbine with specific characteristics and specific loads. Thus, it is not intended to impose restrictions on the use of concrete classes or the geometry of the towers.

\section{Loads and adopted combinations}

\subsection{Load Cases}

In view of all loading cases present in EN 61400-1 [7], "Wind Turbines - Part 1: Design Requirements" for reasons of simplification, aimed at the design of a wind tower, the following two cases are used: one for the turbine in operation and the other for turbine not operating, as well as La Nier [3] and Ma and Meng [2]:

- Power Production ( $D L C 1.6$ ): corresponds to a gust during operation of the turbine. The wind condition is $E O G_{50}$;

- Parked (standing still or idling) (DLC 6.1): corresponds to a gust during a stand-still or idling condition. The wind condition is $E W M_{50}$.

\subsection{Wind loads on the turbine}

The loading at the top of the wind tower from the wind loads and turbine operation are those used by [3] and coming from "WindPACT Turbine Rotor Design Study" [8] for turbines of $5 \mathrm{MW}$ and wind conditions EOG50 and EWM50. The characteristic values of the internal forces are described in Table 1. Note that the resultants are used for both the shear and the bending moment, because the cross section is axisymmetric. For the axial load on the top of the tower is considered, in this case, only the weight of the turbine to both. It is worth noting that the effect of torsional moment was dismissed.

For the non operation condition EWM50, a gust of $3 \mathrm{~s}$ with a speed of $59.5 \mathrm{~m} / \mathrm{s}$ (Class II turbine) was used, while for the operating condition, EOG50, there has been a gust of wind $3 \mathrm{~s}$ to $35 \mathrm{~m} / \mathrm{s}$, both in the rotor hub height of the wind turbine (100 meters). Wind turbines have control systems that prevent their operation at very high wind speeds (cut-out), in order to avoid damaging the machine, which explains the fact that the gust in operation is less than the gust in non operation.

\subsection{Wind loads on the tower}

In order to maintain consistency with the adopted loading for the turbine, as well as make use of the proposal given in [3], except for being prioritized the recommendations of the Brazilian standard, it is necessary to convert the speed of the rotor hub height for usual height of 10 meters used by wind standards. For this purpose, two exponents are adopted for the wind speed profiles for each of the

\section{Table 1}

Loads considered at the top of the tower for a $5 \mathrm{MW}$

\begin{tabular}{|c|c|}
\hline EOG50 & EWM50 \\
\hline \multicolumn{2}{|c|}{$\mathrm{P}_{\mathrm{T}}=\mathrm{m}_{\mathrm{T}} \mathrm{g} \cong 480.076 \mathrm{~kg} \times 9,81 \mathrm{~m} / \mathrm{s}^{2} \cong 4709,55 \mathrm{kN}$} \\
\hline $\mathrm{V}_{\mathrm{T}}=\sqrt{\mathrm{F}_{\mathrm{y}, \mathrm{T}}^{2}+\mathrm{F}_{\mathrm{y}, \mathrm{T}}^{2}}=\sqrt{1057^{2}+128^{2}} \cong 1064,72 \mathrm{kN}$ & $\mathrm{V}_{\mathrm{T}}=\sqrt{\mathrm{F}_{\mathrm{y}, \mathrm{T}}^{2}+\mathrm{F}_{\mathrm{y}, \mathrm{T}}^{2}}=\sqrt{199^{2}+543^{2}} \cong 578,32 \mathrm{kN}$ \\
\hline $\mathrm{M}_{\mathrm{T}}=\sqrt{\mathrm{M}_{\mathrm{y}, \mathrm{T}}^{2}+\mathrm{M}_{\mathrm{y}, \mathrm{T}}^{2}}=\sqrt{5.822^{2}+18.440^{2}} \cong 19.337,25 \mathrm{kN} . \mathrm{m}$ & $\mathrm{M}_{\mathrm{T}}=\sqrt{\mathrm{M}_{\mathrm{y}, \mathrm{T}}^{2}+\mathrm{M}_{\mathrm{y}, \mathrm{T}}^{2}}=\sqrt{21.820^{2}+18.440^{2}} \cong 28.568,27 \mathrm{kN} . \mathrm{m}$ \\
\hline $\mathrm{P}_{\mathrm{T}}$ - Axial load, $\mathrm{V}_{\mathrm{T}}$ - Shear load, $\mathrm{M}_{\mathrm{T}}$ - Bending moment, $\mathrm{m}_{\mathrm{T}}$ - turbine mass. \\
\hline
\end{tabular}


two wind conditions, as follows: $\alpha=0.11$ for $E W M 50$ and $\alpha=0.2$ for EOG50. These exponents are used in the power law of each speed profile and are in agreement with ref. [7]. Thus, the 3 s gusts, with a 50 years return period, with a height of $10 \mathrm{~m}$ adopted are:

EWM50: $v(10)=59,5(10 / 100)^{0,11} \cong 46,19 \mathrm{~m} / \mathrm{s}$

- EOG50: $v(10)=35(10 / 100)^{0,2} \cong 22,08 \mathrm{~m} / \mathrm{s}$

To obtain the wind load along the tower is used the discrete model of ABNT NBR 6123: 1988 [9], since the concrete towers must have a natural frequency as low as possible (the first bending vibration mode) and are thus susceptible to vibration structures. This low rate is desirable because with the increased size of turbine, the saving in weight of the tower that can be achieved with a "flexible" design represents a considerable economic benefit (Hau) [10]. The terrain characteristics such as topography $\left(S_{1}\right)$ and roughness, adopted to calculate the design speed, considering the location of wind tower installation that should focus on the wind energy, are adopted: $S_{1}=1$ and roughness category II (open terrain level or approximately level with few obstacles such as coastal areas, grasslands and heathlands, among others). The value for the topographic factor is justified: in the three "categories" only to deep valleys and protected from the wind, the $S_{1}$ value becomes 0.9 , and for others is at least equal 1.0 and may be greater on top of hills and slopes. The roughness of category II is used to not restrict the implantation site to surface waters (calm sea, lakes and rivers, marshes without vegetation) and, according to ref. [1] in equivalence with the German DIN 1055-4 [11], the larger roughness can be discarded. Regarding the statistical factor, it is used $S_{3}=1,0$, since the wind speed has a 50 years return, with a $63 \%$ probability of being exceeded in one year, and, in addition, it is an industrial building of low occupation factor, which is also part of a power plant.

To obtain the first mode, with the first natural frequency, is made a numerical analysis using the finite element SAP2000 [12], which obtains the eigenvalue problem solution to structures composed by various systems degrees of freedom in free vibration without dampina:

$$
\left[K-\Omega^{2} M\right] \Phi=0
$$

\section{where}

$K$ represents the stiffness matrix, $M$ is the diagonal mass matrix, $\Omega^{2}$ is the diagonal matrix of eigenvalues and $\Phi$ is the eigenvector matrix.

The critical damping ratio $\zeta$, which is important in obtaining the dynamic amplification coefficient $\xi$ and therefore the wind load can be obtained through table 19 of ref. [9], considering the group "Towers and concrete chimneys, variable section," for which $\zeta=0.015$. The modulus used to calculate the vibration mode and the natural frequency of the structure is the secant modulus of elasticity of the concrete because, when it comes to design, in principle, is not known the steel of active and passive reinforcement.

\subsection{Combinations in service limit state and ultimate limit state}

As disseminated in structural design standards, it is common to adopt the method of limit states that, in turn, are divided into: ultimate limit states, which correspond to the exhaustion of the bearing capacity of the structure, and service limit states, which corre- spond to the functional requirements and durability. For each type of limit state is applied one of the wind conditions with their respective gusts, e.g., for the service limit state, the load obtained with the $E O G_{50}$, and for the ultimate limit state, the load obtained using the $\operatorname{EWM}_{50}$ ([3] and [2]).

Because it is a precast and prestressed structure and to avoid the appearance of tensile stresses in the joints between the rings while the structure is in service and for being the gust of wind in operation with a return period of 50 years, a situation that should happen a few times during the lifetime of the structure, it is justified the use of a rare combination for the decompression service limit state. In this sense, the case is characterized as a complete prestressing level for the design of the prestressed concrete section. Thus, combinations of loads recommended by ABNT NBR 8681 [13] that take into account the EOG 50 wind condition can be described by: Decompression Limit State: rare combination, lower fiber:

$$
\begin{aligned}
& S_{d}=S\left(F_{d, s e r}\right)=\sum_{i=1}^{m} F_{g i, k}+F_{q 1, k} \leq S_{l i m} \therefore \\
& S\left(F_{g 1, k}+N_{p \infty}+F_{q 1, k}\right) \leq 0
\end{aligned}
$$

Excessive Compression Limit State: rare combination, superior fiber:

$$
\begin{aligned}
& S_{d}=S\left(F_{d, s e r}\right)=\sum_{i=1}^{m} F_{g i, k}+F_{q 1, k} \leq S_{l i m} \therefore \\
& S\left(F_{g 1, k}+N_{p \infty}+F_{q 1, k}\right) \geq-0,6 f_{c k}
\end{aligned}
$$

The limit value in equation 2.5 is in accordance with the American standard ACI 318:2014 [14], which defines the maximum compressive stress in concrete in service after the loss of prestressing.

With respect to the excessive deformations service limit state, also appears to be no clearly defined simplified criterion for the maximum displacement at the top of the structure, so that here are adopted $\Delta_{\text {máx }}=L / 400$ (largest value in [6]) and $\Delta_{\text {máx }}=L / 250$ . Still, Ma and Meng [2] use $\Delta_{\max }=L / 100$, the Chinese standard, in analogy of wind tower with concrete chimneys, but it will not be adopted in this research. In this study, the displacement at the top of the structure is obtained with rare combination of service using the geometric nonlinearity through $\mathrm{P}-\Delta$ process, present in SAP2000 program, whereas the secant modulus of elasticity of the material and the moment of inertia of the section gross concrete. The same goes for the internal forces in the sections for the others limit states in service.

Since is made use of a wind turbine with known operating frequency of $11.2 \mathrm{rpm}$ or $0.187 \mathrm{~Hz}$ (ref. [3] and [8]), it is desired that the natural frequency of the first vibration mode of the tower avoid the frequency ranges $1 p \pm 10 \%$ e $3 p \pm 10 \%$ (where, $1 p$ is the frequency of the rotor and $3 p$, the blade passing frequency) to avoid resonance effects with the turbine operation (ref. [1]). It is not considered the rotor operating frequency range.

Regarding the ultimate limit state, when the exhaustion of the resistant section capacity, the wind condition to be considered, as already explained, it is the EWM50. This is a normal ultimate combination, which must be made taking into consideration the physical and geometrical nonlinearities. As for the partial safety 


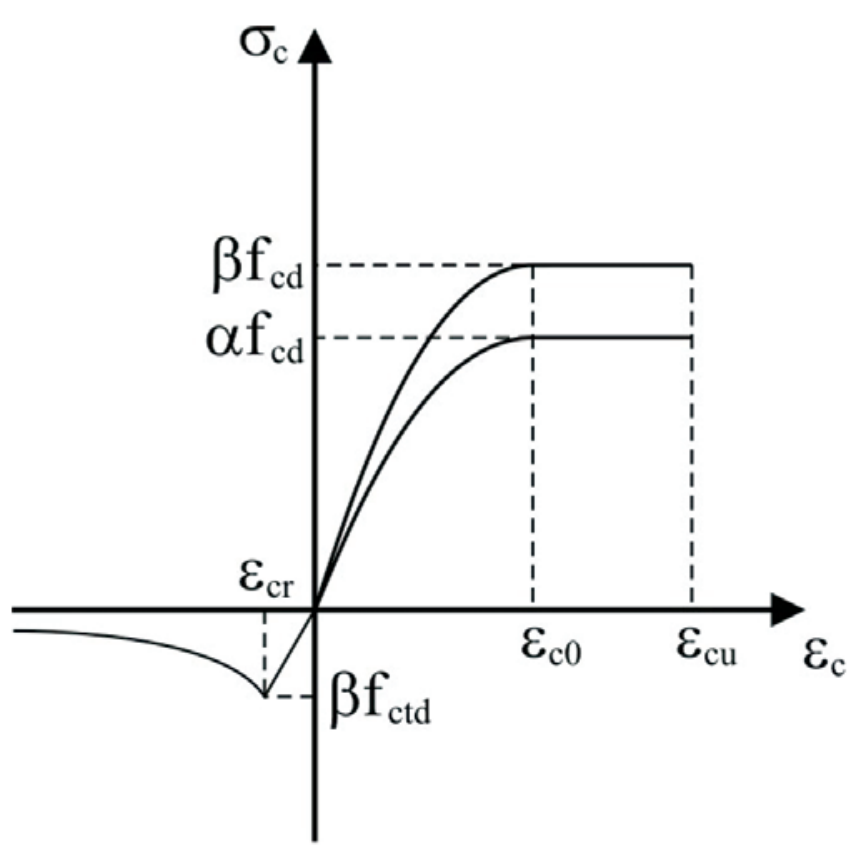

Figure 1

Stress-strain diagram adopted for the concrete

factors for actions, their use depends on the type of combination of action and whether it is acting in a favorable or unfavorable direction. Thus: for the own weight of the structure $\boldsymbol{F}_{g 1, k}$, in the normal ultimate combination, the partial safety factor $\gamma_{f}$ used is weighting is used $\gamma_{g}=1.4$, excluding the case of precast structure [15]; for the variable action $\boldsymbol{F}_{q 1, k}$ caused by the wind that acts directly on the tower, the normal ultimate combination, the adopted partial safety factor is $\gamma_{q 1}=1.4$; the prestressing force $N_{p \infty}$ has a partial safety factor of $\gamma_{p}=0.9$ for the normal ultimate combination; for the actions in the tower from the incidence of wind on the wind turbine, $F_{q 2, k}$, the adopted partial safety factor is the same provided by the ref. [7], $\gamma_{q 2}=1.35$, since the loads from the wind turbine and tower were taken apart.

Thus, the normal combination in the ultimate limit state can be described as:

$$
\begin{aligned}
& S_{d}=S\left(\gamma_{f} F_{k}\right)=S\left(\gamma_{g} F_{g 1, k}+\gamma_{p} N_{p \infty}+\right. \\
& \left.\gamma_{q 1} F_{q 1, k}+\gamma_{q 2} F_{q 2, k}\right)<S_{l i m}
\end{aligned}
$$

In the latter equation, the notation of the indexes has been changed in relation to the Brazilian standard. In fact, it is only considered a main variable action (the wind), which is split into "two" main variable actions parcels, each with its own partial safety factor.

\section{Nonlinear material behavior}

\subsection{Stress-strain relationships}

The Brazilian standard ABNT NBR 6118: 2014 [15] shows, both for calculation of internal forces and deformations (second-order analysis) and for calculation of ultimate resistant internal forces (design of steel area), the parabola-rectangle diagram for stressstrain relationship of concrete in compression is given by:

$$
\begin{aligned}
& \sigma_{c}=f_{c}\left[1-\left(1-\frac{\varepsilon_{c}}{\varepsilon_{c 2}}\right)^{n}\right] \text { for } 0 \leq \varepsilon_{c} \leq \varepsilon_{c 2} \\
& \sigma_{c}=f_{c} \text { for } \varepsilon_{c 2}<\varepsilon_{c} \leq \varepsilon_{c u 2}
\end{aligned}
$$

Where

$f_{c}$ is the compression strength of concrete with appropriate partial safety factor to the type of analysis performed. According to ref. [15] and França [16], the calculation of displacement, $f_{c}=\beta f_{c d}=1,10 f_{c d}$, which is already multiplied by the coefficient for maintained load effect, the Rüsch effect, and in verifying the rupture, $f_{c}=\alpha f_{c d}=0,85 f_{c d}$ ( $\alpha$ is the very Rüsch effect). The design compression strength of concrete $f_{c d}$ is the characteristic strength lessened by the partial safety factor $\gamma_{c}=1,4$. The values of parameters:

$\varepsilon_{c 2}$ (specific shortening deformation of concrete at the beginning of "yielding"), $\varepsilon_{c u 2}$ (specific shortening deformation concrete at rupture) and the exponent $n$ in the equation, differ depending on whether the concrete belongs to C50 class or is of C55 to C90 class. It is not considered the tensile strength of concrete when verifying the rupture, once the closer is a section of its resistance capacity, lower is the difference between the pure State II and the State II. However, in order not to penalize so much the section, when performing the second-order analysis, a partial safety factor $\beta=1,10$ is adopted also for the stress-strain relationship for concrete in tensile. The stress-strain diagram adopted for the upward stretch to tensile is considered linear elastic to a calculation of design tensile strength of concrete, $f_{c t d}$, making use of the initial tangent modulus of elasticity. From the corresponding strain at maximum tensile stress is set to the downward stretch the equation proposed by Araújo [17], except for the design values and partial safety factors:

$\sigma_{c t}=E_{c i} \varepsilon_{c t}$ for $0 \leq \varepsilon_{c t} \leq \varepsilon_{c r}$

$\sigma_{c t}=\beta f_{c t d}\left(\frac{\varepsilon_{c r}}{\varepsilon_{c t}}\right)^{0,6}$ for $\varepsilon_{c t}>\varepsilon_{c r}$

Where

$\varepsilon_{c r}=\beta f_{c t d} / E_{c i}$ is the concrete's cracking deformation. The stressstrain diagram of concrete is shown in Figure 1.

The stress-strain diagrams for passive and active reinforcement are shown in Figure 2. The partial safety factor for the two types of steel is $\gamma_{s}=1,15$. For passive reinforcement steel is considered a perfect elastoplastic behavior, both in tensile as in compression, for the calculation of deformations (using the diagram with $f_{y k}$ ) or section design (using the diagram with $f_{y d}$ ). It is adopted the CA-50 steel and an elasticity modulus of $E_{s}=200$. The tensile deformation is limited to the value of $10 \%$ as a rupture criterion. For steel the active reinforcement, generally a bilinear behavior may be taken for both calculation of the deformations (using the diagram with characteristic values) and design (using the diagram with design values). The strands adopted are CP-190-RB type, with an initial tangent modulus of $E_{p}=200$ and a specific deformation $\varepsilon_{p u k}=40 \%$. Other quantities assume values according to the ABNT NBR 6118: 2014. For Ultra High Performance Fiber Reinforced Concrete (UHP$\mathrm{FRC}$ ), in view of the lack of experimental data, the following sim- 

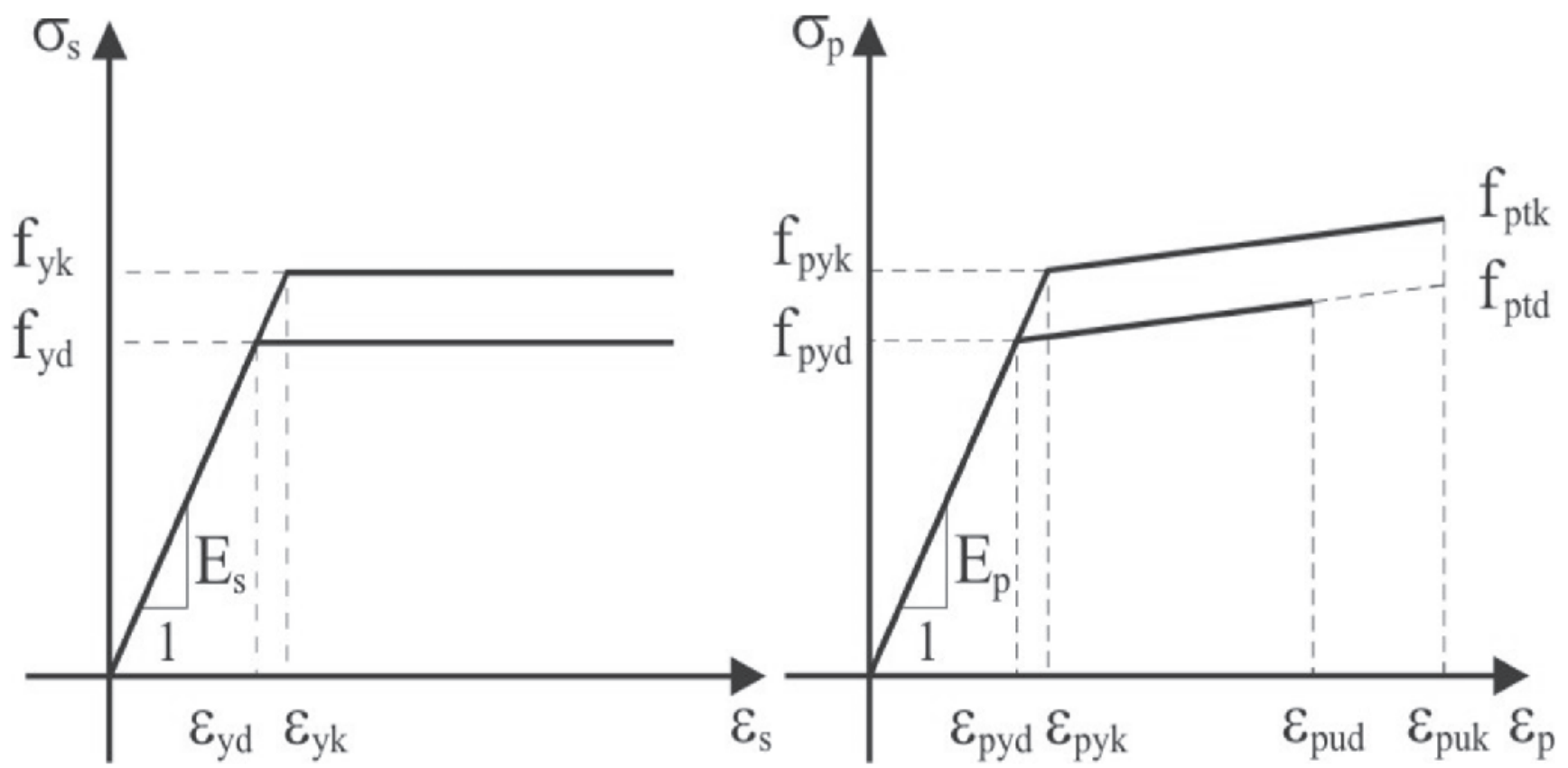

Figure 2

Stress-strain diagrams adopted for the passive and active reinforcements

plifications and considerations on tensile diagram stress-strain are adopted, used for the ultimate limit state. As in Spasojević [18], from direct tensile tests by Jungwirth [19], are adopted an elastic linear domain and, after this, pseudoplastic domain limited level of $2.5 \%$, which occurs multiple microcracking, but without the deformation start to locate on one or more main macrocracks. For simplification, it was disregarded the last domain that would be a softening domain, in which no more tension relates directly to the deformation, but with the crack opening. However, it is intended to

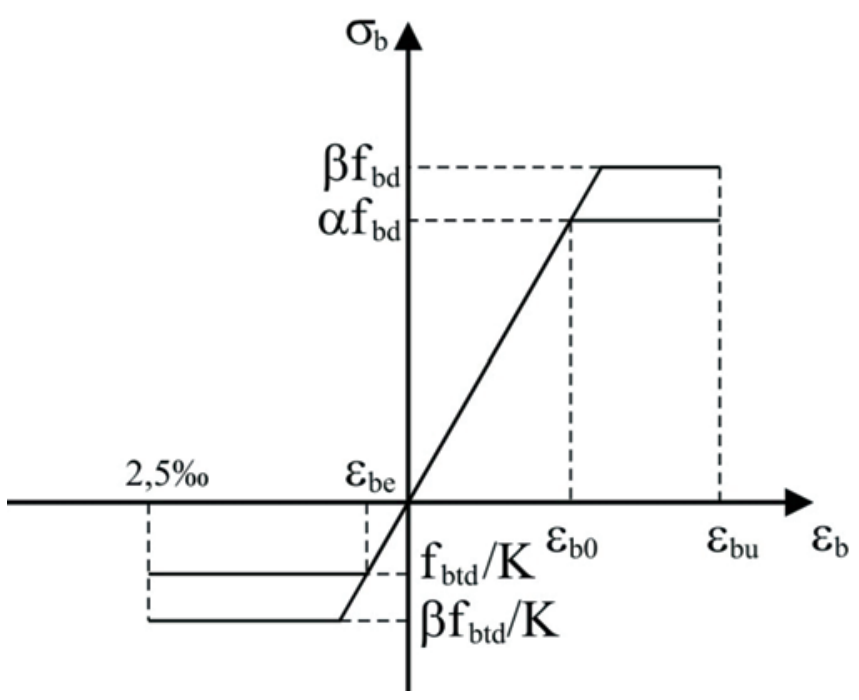

Figure 3

Stress-strain diagrams adopted for the proposed UHPFRC verify in future work the influence of consideration of the softening domain for UHPFRC.

The mechanical properties and characteristic values used for $\mathrm{UH}-$ PFRC - "Beton Spécial Industriel" (BSI) - are also present in the interim recommendations of the AFGC [2] and are $f_{b k}=180 \mathrm{MPa}$, $f_{b t k}=9.1 \mathrm{MPa}$ e $E_{b}=65 \mathrm{GPa}$. The partial safety factor is $\gamma_{b}=1.3$ and in the case of tensile is still considered an additional coefficient of orientation of the fibers $K=1.25$ (when it does not consider local effects). The same coefficients $\alpha$ and $\beta$ are used, for design and second-order analysis, respectively (Figure 3). As the AFGC mentions nothing about the effect Rüsch at tensile, it takes only the $\beta$ coefficient $=1.10$ to not penalize and overestimating deformations.

\subsection{Moment-curvature-axial load diagrams}

To obtain the bending moment-curvature-axial load diagrams is necessary to establish hypotheses about the deformed configuration of the bar, considered slender. As usually employed, are also admitted the following hypotheses: Navier-Bernoulli hypothesis, in which the cross sections, initially plane and normal to the bar axis, remain plane and normal to the deformed axis to the ultimate limit state, thus distortions caused by shear stresses can be neglected (small deformations); there is perfect adhesion between the active and passive reinforcement and concrete; stress-strain diagrams for describing the nonlinear behavior of materials are those described in the previous section; and the rupture cross section occurs because the deformations limits are reached for the concrete and/or for steel. From the Navier-Bernoulli hypothesis, it has to displacement field within the bar on plane:

$$
u(x, y)=u_{0}(x)-y \frac{d v}{d x}, \quad v(x, y)=v(x)
$$


Therefore, it results in a linear distribution of longitudinal deformations along the height of the cross section. Assuming for curvature of barycentric axis of the bar, the second derivative of $v$, the deformation for a generic point in cross section is given by:

$$
\varepsilon_{x}=\varepsilon_{0}-y \frac{d^{2} v}{d x^{2}}=\varepsilon_{0}+y \chi
$$

Because of the perfect adhesion hypothesis, the deformations in the passive and active reinforcement are also described by the same equation above. For the case of prestressing steel, as in grouted post-tensioned tendons, it is still necessary to consider the initial deformation of prestrain of prestressing steel $\Delta_{\mathcal{E}_{p i}}$. Thus, the deformations for each component of section become:

$\varepsilon_{c i}=\varepsilon_{0}+y_{c i} \chi, \varepsilon_{s i}=\varepsilon_{0}+y_{s i} \chi, \varepsilon_{p i}=$ $\Delta \varepsilon_{p i}+\Delta \varepsilon_{p d}=\Delta \varepsilon_{p i}+\varepsilon_{0}+y_{p i} \chi$

With centered prestressing, the post-tensioning prestrain deformation is given by:

$$
\Delta \varepsilon_{p i}=\gamma_{p}\left[N_{p \infty}\left(\frac{1}{E_{p} A_{p}}+\frac{1}{E_{c s} A_{g}}\right)\right]
$$

The annular cross section (see Figure 4) has $n$ reinforcement bars, and half of these uniformly arranged bars in each section perimeter, internal and external. The cables are arranged uniformly along the perimeter of the middle radius of the section and are composed of the same amount of strands. A generic bar has an area equal to $A_{s i}$ and coordinates $\left(x_{s i}, y_{s i}\right)$ and a generic cable has an area equal to $A_{p i}$ and coordinates $\left(x_{p i}, y_{p i}\right)$.

Applying the equilibrium equations, internal forces are obtained in the cross section for combined compression and bending moment:

$$
N=\int_{A_{c}} \sigma_{c} d A+\sum_{i=1}^{n_{s}} \sigma_{s i}\left(\varepsilon_{s i}\right) A_{s i}+\sum_{i=1}^{n_{p}} \sigma_{p i}\left(\varepsilon_{p i}\right) A_{p i}
$$

$M=\int_{A_{c}} \sigma_{c} y d A+\sum_{i=1}^{n_{s}} \sigma_{s i}\left(\varepsilon_{s i}\right) y_{s i} A_{s i}+$

$\sum_{i=1}^{n_{p}} \sigma_{p i}\left(\varepsilon_{p i}\right) y_{p i} A_{p i}$

Where it disregards the second bending moment due to axisymmetric section. The integrals are taken over the entire area of concrete and solved numerically by Simpson's rule, performing the integration over the thickness and circumference (radial and circumferential layers).

The bending moment-curvature-axial load relationship is obtained by controlling the deformations for which are being adopted $x$ curvatures, incrementally, calculating thus the internal forces $(N, M)$ until they are balanced with external forces $\left(N_{e x t}, M_{e x t}\right)$. The procedure described can be accomplished by iterative methods, in example, by the Newton-Raphson method. In this case, it is intended to obtain the root of the function defined by:

$$
\begin{aligned}
& f(N)=N_{e x t}-N=N_{e x t}-\left(\sum_{i=1}^{n_{c}} \sigma_{c i}\left(\varepsilon_{c i}\right) \Delta A_{c i}+\right. \\
& \left.\sum_{i=1}^{n_{s}} \sigma_{s i}\left(\varepsilon_{s i}\right) A_{s i}+\sum_{i=1}^{n_{p}} \sigma_{p i}\left(\varepsilon_{p i}\right) A_{p i}\right)
\end{aligned}
$$

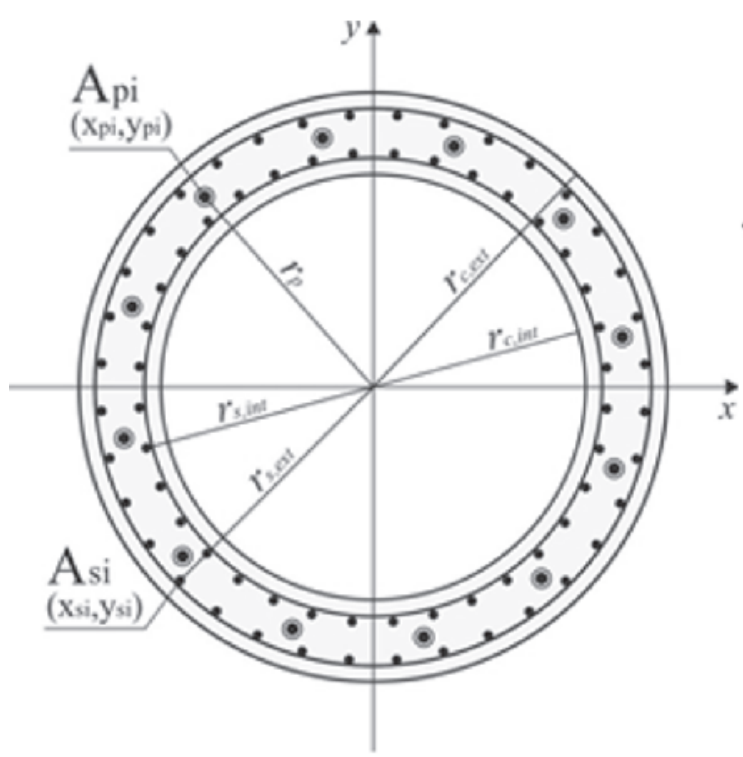

- Active reinforcement

- Passive reinforcement

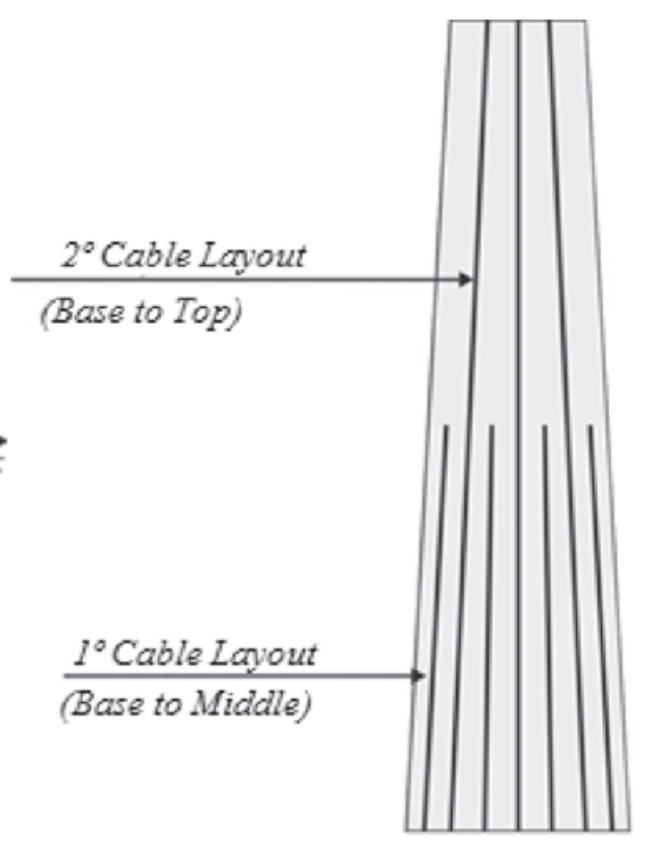

Tower with two cable layouts

\section{Figure 4}

Schematic diagram of anular cross section providing active and passive reinforcements and cable layouts along the tower 


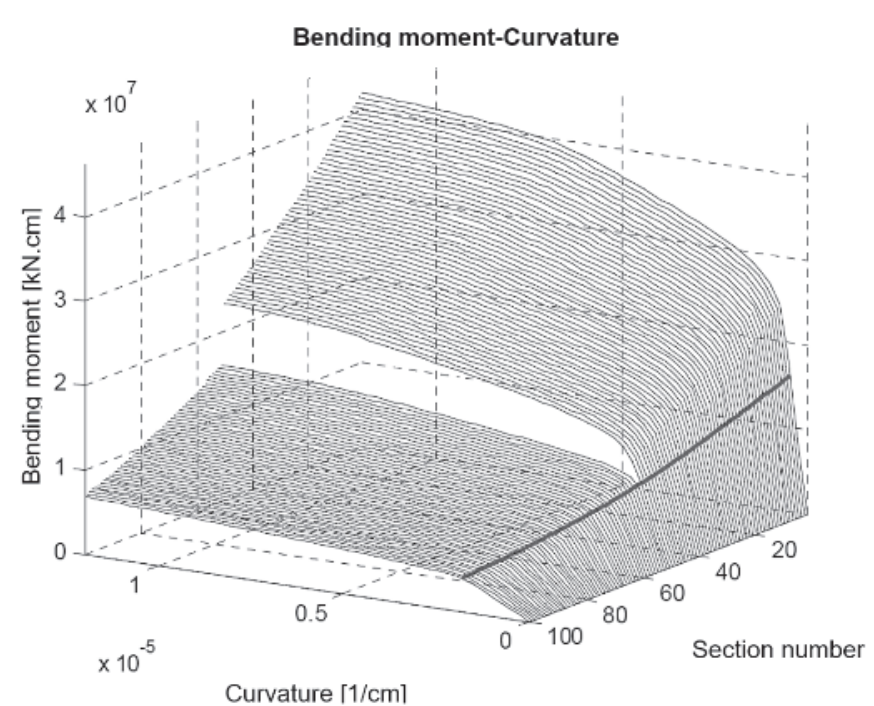

Figure 5

Bending moment-curvature diagrams associated with the internal forces in the ultimate combination (bending moment and axial load): sections along the tower for the complete prestressing level used along the 100 sections. The red line corresponds to the couple bending moment-curvature associated with internal forces in the ultimate combination

$\varepsilon_{0 i+1}=\varepsilon_{0 i}-\frac{f(N)}{f^{\prime}(N)}$

In this root function calculation so as to improve the convergence of the algorithm, an adjustment is applied to the Newton method, making it more robust. As in the bi-secant method, should be imposed, initially, the search of solution range. For each new value of the variable obtained within the range, adapts the solution interval, reducing it. If this new value is out of range limits, the latter solution interval and the corresponding values for the function are employed in the bi-secant method, obtaining a value inevitably internal to the range. Then, reduces the range and the Newton method is used again. This removes the instability problem. The results obtained for the previous sections are stored to serve as new estimate, ensuring even greater velocity to obtain the solution.

\subsection{Ultimate limit strain distribution}

The calculation of passive steel in prestressed section is done by means of distribution of limit strain in the ultimate limit state according to the ABNT NBR 6118: 2014 (Figure 6) also being accepted as a design method for UHPFRC (ref. [2]) by simply changing the corresponding deformations. The procedure consists in finding, iteratively, the depth $x$ of the neutral line, which is in the range of 0 to $\infty$, in combined compression and bending moment. The stresses are then obtained in accordance with the deformations imposed by distribution of limit strain, as well by the depth of the neutral line, and the solution is found by solving the same equilibrium equations with the adapted Newton method, as presented in the previous section. As the arrangement of the reinforcement is known, restriction is not made to ultimate strains ("design domains") as in the case of columns.

\section{Design of prestressed concrete slender columns}

The tower is adopted with an $L$ height of $100 \mathrm{~m}$, divided into 25 rings, each with $4 \mathrm{~m}$ high. The sections have dimensions that vary linearly from top to bottom of the structure. For each ring, the passive steel area is considered constant. As for the finite element method, each ring is divided into sufficient number of one-dimensional elements with constant geometry each, referring to the midpoint of the element. Thus are sufficient four elements per ring, resulting in 100 elements. The structure is considered to be clamped on the base.

\subsection{Active reinforcement}

The internal forces in the sections intended for calculating the active reinforcement is obtained by the nonlinear geometric analysis, by considering the P- $\Delta$ effect (CSI [12]) with the secant modulus of elasticity $E_{c s}$.

Are considered for the tower, two cable layouts $t_{r}=2$, aiming at reducing the total length of sheaths and cables. Explained from some considerations: the length of each layout is taken as a multiple of the total length on the number of layouts, $i . L / t_{r}$, with $1 \leq i \leq t_{r}$; the horizontal variation of the layout is negligible as $\Delta \mathrm{y} \ll \Delta \mathrm{z}$, then $\Delta \mathrm{s}=\sqrt{\Delta \mathrm{y}^{2}+\Delta \mathrm{z}^{2}} \cong \Delta \mathrm{z}$; the number of strands is the same for each cable; it is assumed, as estimated, that the variation of the prestressing force obtained for the sections is linear, from the bottom to the top. Note that the stress at the top is considered to approximately zero (small tensile stress), then each segment of the tower $L / t_{r}$, has $i . n_{\text {cables }} / t_{r}$ cables to $1 \leq i \leq t_{r}$. Thus, adopting the number of cables on the base of the tower as a reference, $n_{\text {cabos }}$, has to the total length of cables and sheaths:

$$
\begin{aligned}
& L_{\text {cables }}=\frac{L}{t_{r}} \sum_{i=1}^{t_{r}} n_{\text {cables }} \frac{i}{t_{r}}=n_{\text {cables }} \frac{L}{t_{r}^{2}} \frac{t_{r}\left(t_{r}+1\right)}{2}= \\
& \frac{\left(t_{r}+1\right)}{2 t_{r}} n_{\text {cables }} L=\gamma n_{\text {cables }} L
\end{aligned}
$$

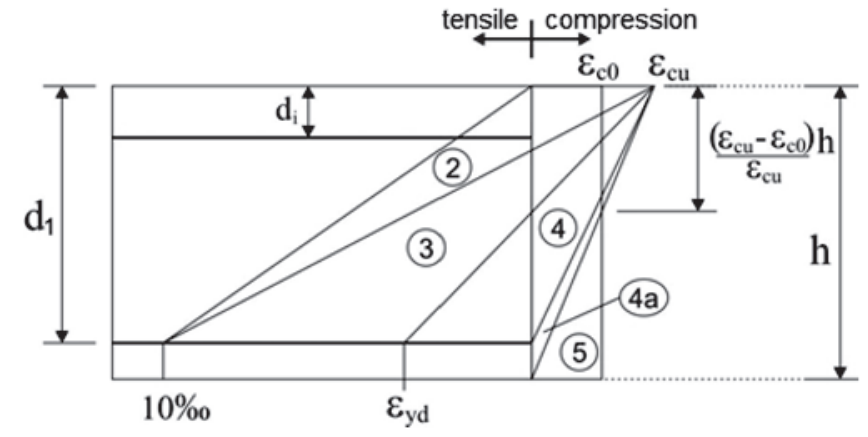

Figure 6

Design domains (or Ultimate Limit Strain Distribution) for a cross section (adapted from NBR 6118 (15)) 
Therefore, as $\gamma$ tends slowly to 0.5 as the number of layouts tends to infinity and its value is already $\gamma=0,75$ with $t_{r}=2$, an intermediate value between the function limits, it remains adopted that last value.

Are adopted seven wire strands with nominal diameter of $12.7 \mathrm{~mm}$, defining a minimum value of 1 and a maximum of 12 strands for cable, respecting the spacing limits between cable axes, minimum of $30 \mathrm{~cm}$ and maximum of $120 \mathrm{~cm}$ (same adopted in slabs) [15]. Is adopted from among the possible options, the one with the largest amount of strands, therefore, less cables.

It is also made a recalculation of prestressing force losses, since it is fir-st necessary to estimate the losses to then check if these correspond to calculated. This allows to correct and to optimize the area of prestressed steel. The anchor type is active-passive towards bottom-up. Are calculated for all sections and for each cable layout, both immediate as progressive losses: friction, accommodation of anchoring wedges, elastic shortening of concrete, shrinkage, creep and relaxation.

$$
\mathrm{n} \sigma_{p, c+s}\left(t_{\infty}, t_{0}\right)=\frac{\varepsilon_{c s}\left(t_{\infty}, t_{0}\right) E_{p}+\alpha_{p}\left(\sigma_{c, p 0 g}+\sigma_{c, g}\right) \varphi\left(t_{\infty}, t_{0}\right)+\alpha_{p} \sum_{i}\left[\mathrm{n} \sigma_{c, g i} \varphi\left(t_{\infty}, t_{i}\right)\right]}{\left[1-\alpha_{p}\left(\frac{\sigma_{c, p 0 g}}{\sigma_{p 0}}\right)\left(1+\frac{\varphi\left(t_{\infty}, t_{0}\right)}{2}\right)\right]}
$$

It is remarkable the great influence of the parasitic deviations in friction losses $\left(\Delta N_{p 0} / N_{p i}=\left[1-e^{-(\mu \alpha+k x)}\right]\right)$, since they do not depend on the cable deviation angle over their path, but the length between the anchors which in this case is approximately 100 meters (through $k x$ ). Because of this, it should be taken as low as possible value for the friction coefficient $\mu$ and for that, we adopt the value of 0.10 (lubricated metal sheath). This already corresponds to a near $9.5 \%$ loss in prestressing force for a cone frustum tower of same height.

The losses due accommodation of anchoring wedges are obtained numerically and iteratively through the bi-secant method, taking the displacement value on the accommodation of anchoring as $\mathrm{n} w=6 \mathrm{~mm}$ :

$$
f(w)=\mathrm{n} w-\frac{2 \int_{0}^{w}\left[N_{p 0}(x)-N_{p 0}(w)\right] d x}{E_{p} A_{p}}
$$

Where $w$ is any point along the cable longitudinal length $L$. If the equilibrium point is greater than this longitudinal length (considering active-passive anchoring) it is just needed to change the variable $w$ to $P$, the prestressing force value at the end of length

$$
L: f(P)=\Delta w-2 \int_{0}^{L}\left[N_{p 0}(x)-P\right] d x /\left(E_{p} A_{p}\right) .
$$

In this case, the solution is in the range $P \leq N_{p 0}(L)$. If there is no amount due to mobilized permanent load and considering a large number of cables, the loss of elastic shortening along the tower is:

$$
\Delta N_{p}=\Delta \sigma_{p} A_{p}=\frac{1}{2} \frac{E_{p}}{E_{c i}} \frac{N_{p 0}}{A_{c}} A_{p}
$$

If each group of cables, the minor and major layout, is prestressed in this order, the elastic shortening of the concrete caused by pre- stressing of the second group generates an additional loss in the prestressing force of the first cables group. Losses related to this slackening are taken into account by the displacement compatibility between the cables and the lower half of the tower.

In calculating the progressive losses, it is pertinent to consider that: the loads due to the tower own weight, the prestressing and the weight of the turbine are applied in close enough phases; the cables are uniformly distributed in the section, each cable group treated as a resulting cable; there is perfect adhesion between the concrete and reinforcement and the structural element remains in state I. To obtain the creep coefficient, $\varphi\left(t_{\infty}, t_{0}\right)$, and retraction of specific deformation, $\varepsilon_{c s}\left(t_{\infty}, t_{0}\right)$ are considered: the date of application of loads $t_{0}=30$ days and environmental average humidity of $75 \%$ using table 8.2 of ref. [12]. Even with the considerations regarding the loading application and coefficients, the losses by shrinkage and creep, and relative relaxation, are obtained by the general method of calculation, the formula derived from the average tension method in CEB-FIP 78 [20], as in Cholfe Bonilha

$$
\begin{aligned}
& \mathrm{n} \sigma_{p r, r e l}\left(t_{\infty}, t_{0}\right)=\mathrm{n}_{p r}\left(t_{\infty}, t_{0}\right) \\
& {\left[1-2 \frac{\left|\mathrm{n} \sigma_{p, c+s}\left(t_{\infty}, t_{0}\right)\right|}{\sigma_{p 0}}\right]}
\end{aligned}
$$

For pure relaxation losses, $\Delta \sigma_{p r}\left(t_{\infty}, t_{0}\right)$, the values from ABNT NBR 6118:2014 are used.

As for UHPFRC, according to the AFGC [2], after heat treatment, the shrinkage does not exist and the creep coefficient has a value of $\mathbf{0 . 2}$. This is approximately equivalent to $14 \%$ of the creep coefficient expected to $\mathrm{C} 50$ to $\mathrm{C} 90$ class concrete with the fictional thickness of $30 \mathrm{~cm}, \varphi\left(t_{\infty}, t_{0}\right)=1.4$.

\subsection{Longitudinal passive reinforcement: parameters}

For the position of the steel bars in section is adopted a distance $d^{\prime}=7 \mathrm{~cm}$ between the centroid of the bar and the face of the corresponding section, outer or inner. This value is supported on the following assumptions: the diameter initially adopted for the bars is $40 \mathrm{~mm}$ which, added to the diameter of the transverse reinforcement, which is in turn of at least $1 / 4$ of the longitudinal reinforcement - just $10 \mathrm{~mm}$ - as well as the nominal concrete cover of reinforcement, $35 \mathrm{~mm}$ for CCA II [15], it is possible to obtain an amount of $6.5 \mathrm{~cm}$, slightly lower than adopted.

Regarding the amount of bars, is taken a sufficient amount so that is possible to consider a uniform distribution making insignificant the difference in steel and in bending moment-curvature relationship of a section. As the smallest thickness used in section is 20 $\mathrm{cm}$, it is found that the maximum spacing of $40 \mathrm{~cm}$ longer meets this requirement.

For each ring of $4 \mathrm{~m}$ in height is used the largest areas of the steel 
obtained at the ends of its constituent elements. Then, each ring has the same diameter and amount of bars, providing a staggering of the longitudinal reinforcement.

The minimum reinforcement is calculated from the design of the section subjected to a minimum bending moment $M_{d, \min }=0,8 W_{0} f_{c t k \text {, sup }}$ , where $W_{0}$ is the strength modulus of the gross cross section of concrete on the fiber more tensioned. Finally, the geometric rate of passive reinforcement is such that $\rho_{s} \geq \rho_{\text {min }}-\rho_{p} \geq 0,5 \rho_{\text {min }}$, which respects the absolute minimum rate $\rho_{\text {min }}=0,15 \%$.

\subsection{Longitudinal passive reinforcement: design by nonlinear model}

The model described here uses the exact method due to the tower slenderness and is, in a way analogous to that described by Araújo [22], except for the use of prestressing and some simplifications to make the coupling between the algorithm developed in MATLAB and finite element program, SAP2000.

When dimensioning the passive steel reinforcement, the load combination is used in the ultimate limit state in a non-linear geometrical analysis. Therefore, it is used, initially, $E_{c s}$, as well as the moment of inertia of the gross concrete section. Made the first calculation and using the internal forces $\left(N_{d}, M_{d}\right)$ in the design of passive steel area, it is possible already include the same steel area to obtain the bending moment-curvature-axial load diagrams along the sections.

Hence, from the pairs of internal forces and bending momentcurvature-axial load diagrams obtained for the midpoints of each element along the structure, the new secant flexural stiffnesses are calculated corresponding to the point $\left(M_{d}-\chi-N_{d}\right)$ in diagrams. As can be seen in Figure 5, the normal force is implicit in the bending moment-curvature diagram of each section along the tower. It is noted in this figure that the reduction in the prestress force (axial force) in the upper half of the tower, due to the portion of the cables are anchored in the middle, causes a reduction in section resistant bending moment as well as in cracking moment, compared to half of the tower that receives the axial force from all cables.

Each new calculated rigidity is introduced into the stiffness matrix of each element in the finite element program through changing the moment of inertia of the section, by relation

$E I_{\text {sec,calc }} / E I_{\text {sec, inicial }}$. There shall be a new nonlinear geometric analysis, generating new internal forces and displacements, resulting stiffness and adapting to new elements. This procedure is repeated until the internal forces and displacements converge.

After this step, it is perfomed again the design of the steel passive area, repeating the whole procedure, since the internal forces and displacements are different from those first obtained. For example, if the displacement is less than the initial, bending moments are reduced and thus the obtained steel new area will be smaller than the original. However, if there is an increase in displacement, a greater area is obtained for steel. This procedure allows, setting a criterion for its completion (as convergence of displacements and internal forces and consequent reduction in the difference between passive steel areas), to obtain an optimal steel area (ref. [1]).

\subsection{Shear design}

In contrast to the extensive use of the hollowed and solid circular sections, for example, columns, poles, towers and chimneys and tanks, normative references generally do not propose any specific formulation for the evaluation of shear strength. As described by Teixeira et al. [23], the application of the equation used in rectangular sections to those sections would imply some problems such as: - Applicability of expression used to determine

- $V_{r d 2}$, resistant shear force calculation regarding the ruin of compressed diagonals of concrete;

- Definition of the

- $b_{w}$ value for the calculation of

- $V_{c}$, amount of shear force resisted by complementary mechanisms to truss;

- Doubts about the efficiency of circular stirrups on shear force resistance when determining

$V_{s w}$, amount of shear force resisted by transverse reinforcement. As for the efficiency of circular stirrups on shear force resistance in circular sections, Turmo et al. [24] presents a formulation deduced theoretically and empirically proven to the contribution of the transverse reinforcement, considering both vertical and spiral stirrups. In the case of annular sections, the contribution of transverse reinforcement formed by vertical stirrups is given by stirrups number of the product through the crack, multiplied by the mechanical strength of the stirrup and the average slope of the stirrups at the intersection with the fissure. Simplifying the expression, [24] it is obtained the same expression as used for rectangular section, allowing the conclusion that the shear stresses have the same orientation of the stirrups, which entails that the efficiency factor have value of 1 in the annular section:

$$
V_{s R d}=z \cdot \cot \theta \cdot A_{\phi} \cdot f_{y k, t}, V_{s w}=\frac{2 A_{\phi}}{p} \cdot z \cdot f_{y k, t} \cdot \cot \theta
$$

One way to obtain the $V_{c}$ value is, according to [23], estimate it as the first crack shear, considering state I for the concrete, regarding the maximum tensile stress (in the height of the section centroid). Assuming that the shear stress is uniform through the thickness of the wall, acting parallel to the contour of the section and using the antisymmetry condition of the shear stress in symmetrical sections in shear flow formula, the shear stress $\tau_{s}$ to annular section not cracked can be estimated from $\tau_{s}(s)=V \operatorname{sen} \varphi /\left(\pi R_{m} t\right)$. Thus, the maximum shear stress that occurs in the height of the section centroid will have a value of $\tau_{s, \text { max }}=2 \mathrm{~V} / A_{c}$. And so the shear force corresponding to the first shear crack is given by $V_{c}=\tau_{s, \text { max }} A_{c} / 2=f_{c t} A_{c} / 2$. Since the thin wall sections can be considered as subject to plane stress state, neglecting the stress along the thickness $\sigma_{3}$, the proposed idea can be extended to account longitudinal and circumferential prestressing centered. By material strength, placing $\sigma_{1}=f_{c t}$ and $\tau_{x y}=\tau_{\text {máx }}=2 \mathrm{~V} / A_{c}$, the main stresses $\sigma_{1,2}$ can be placed as a function of shear force:

$$
\begin{aligned}
& \sigma_{1,2}=\frac{\sigma_{x}+\sigma_{y}}{2} \pm \sqrt{\left(\frac{\sigma_{x}-\sigma_{y}}{2}\right)^{2}+\tau_{x y}^{2}} \therefore V_{c}= \\
& \frac{A_{c}}{2} \sqrt{\left(f_{c t}-\sigma_{m e ́ d}\right)^{2}-\left(\frac{\sigma_{x}-\sigma_{y}}{2}\right)^{2}}
\end{aligned}
$$

The $\sigma_{x}$ and $\sigma_{y}$ stresses can be treated as stresses due to centered longitudinal and transverse circumferential prestressing 
forces, respectively. Note that here $X$ refers to the longitudinal axis of the bar and $y$ to one of the orthogonal axes.

Therefore [23], when calculating $V_{c}$ and $V_{r d 2}$, a way to eliminate difficulty in determining the $b_{w}$ value would be using the concept of effective area, as the example of NBR 8800 [25] or Merta and Kolbitsch [26] , replacing the $b_{w} d$ product, although this replacement requires more theoretical and/or experimental basis. Hence, considering the concept of effective area of ABNT NBR8800 and using the smallest width of the section $b_{w}=2 t$, results:

$$
A_{e f}=V /\left(2 V / A_{c}\right)=0,5 A_{c}=\pi R t=b_{w} d=
$$$$
2 t d \therefore d=\pi R / 2=\pi h / 4 \cong 0,785 h
$$

It is noted that it is a value very close to $0.8 h$, which is a lower limit where there is a prestressing reinforcement along the height, since there reinforcement along the face tensioned so as to satisfy the criteria according to [15 ].
To compare the $V_{c}$ value with the experimental data, will be admitted to $f_{c t}$, the lower value of the characteristic strength of concrete strength, $f_{c t k, \text { inf }}=0.7 f_{c t m}$, depending on the concrete strength: if the class is less than or equal to $\mathrm{C} 50$, is used $f_{c t m}=0.3 f_{c k}^{2 / 3}$, if it is greater, $f_{c t m}=2.12 \ln \left(1+0.11 f_{c k}\right)$ and, for the characteristic compressive strength, is used $f_{c k}=\left(f_{c m}-8\right) \mathrm{MPa}$. For the transverse reinforcement, the following adoptions will be made: the angle $\theta$ of the compression strut is $45^{\circ}$; the distance from extreme compression fiber to centroid of longitudinal tension reinforcement will be considered equal to $d=0.8 h$; the stress in the transverse reinforcement equal to the characteristic yield stress $f_{y}=f_{y k}=50$ $\mathrm{kN} / \mathrm{cm}^{2}$; and the stirrups are spiral.

The design resistant shear force on the failure by diagonal tensile, $V_{R d 3}$, is the sum of $V_{c}$ and $V_{s w}$. Table 2 shows the values of the geometrical and mechanical parameters of the tested beams by Völgyi et al. [27] and the comparison between the maximum shear

\section{Table 2}

Comparison between the experimental test from Völgyi et al. (27) and proposed model

\begin{tabular}{|c|c|c|c|c|c|c|c|c|c|c|c|c|c|c|}
\hline 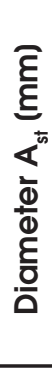 & $\begin{array}{l}\bar{\varepsilon} \\
\mathcal{0}\end{array}$ & 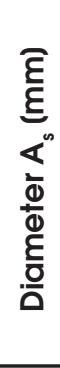 & $\frac{5^{0}}{c^{\infty}}$ & $\frac{\bar{\varepsilon}}{\mathcal{E}}$ & $\underset{\underline{\underline{U}}}{\bar{E}}$ & $\underbrace{\overline{\vec{v}_{0}}}_{\alpha^{\bar{\nabla}}}$ & $\frac{\bar{E}}{\mathcal{U}^{E}}$ & 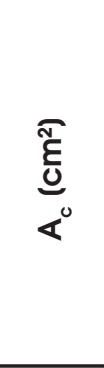 & $\sum_{-0}^{\overline{0}}$ & 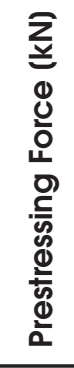 & 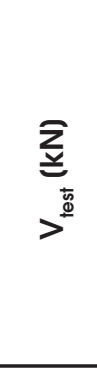 & 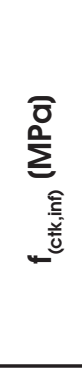 & $\begin{array}{l}\underset{z}{z} \\
>^{\circ}\end{array}$ & $>_{>^{\frac{0}{2}}}^{\gtrless^{\frac{5}{2}}}$ \\
\hline- & 0 & 12 & $12 / 0$ & 5,7 & 9,3 & 15 & 12,15 & 435,1 & 72,9 & 0 & 68,6 & 3,11 & 67,70 & 0,99 \\
\hline- & 0 & 12 & $12 / 0$ & 9,6 & 5,4 & 15 & 10,20 & 615,2 & 70,2 & 0 & 95,0 & 3,06 & 94,02 & 0,99 \\
\hline - & 0 & 16 & $12 / 0$ & 6,4 & 8,6 & 15 & 11,80 & 474,5 & 66,9 & 0 & 78,0 & 2,89 & 68,49 & 0,89 \\
\hline 5 & 15 & 16 & $12 / 0$ & 5,5 & 9,5 & 15 & 12,25 & 423,3 & 72,9 & 0 & 115,0 & 3,11 & 94,13 & 0,82 \\
\hline 5 & 15 & 12 & $12 / 0$ & 5,7 & 9,3 & 15 & 12,15 & 435,1 & 66,9 & 0 & 105,0 & 2,99 & 93,24 & 0,89 \\
\hline 5 & 15 & 16 & $12 / 0$ & 9,3 & 5,7 & 15 & 10,40 & 604,8 & 70,2 & 0 & 158,0 & 3,06 & 120,7 & 0,76 \\
\hline 5 & 11 & 16 & $12 / 0$ & 9,1 & 5,9 & 15 & 10,50 & 597,5 & 66,9 & 0 & 187,0 & 2,99 & 127,8 & 0,68 \\
\hline 5 & 15 & 16 & $8 / 4$ & 5,8 & 9,2 & 15 & 12,10 & 441,0 & 62,5 & 148 & 140,0 & 2,89 & 121,9 & 0,87 \\
\hline 5 & 15 & 16 & $8 / 4$ & 9,2 & 5,8 & 15 & 10,40 & 601,2 & 64,8 & 88 & 141,0 & 2,94 & 136,4 & 0,97 \\
\hline 5 & 15 & 16 & $8 / 4$ & 9,3 & 5,7 & 15 & 10,35 & 604,8 & 69,8 & 106 & 146,0 & 3,05 & 143,9 & 0,99 \\
\hline 5 & 15 & 16 & $8 / 4$ & 9,3 & 5,7 & 15 & 10,35 & 604,8 & 62,5 & 228 & 163,0 & 2,89 & 160,8 & 0,99 \\
\hline 5 & 15 & 16 & $8 / 4$ & 9,5 & 5,5 & 15 & 10,25 & 611,8 & 69,7 & 238 & 161,5 & 3,05 & 168,9 & 1,05 \\
\hline 5 & 15 & 0 & $0 / 12$ & 9,2 & 5,8 & 15 & 10,40 & 601,2 & 72,2 & 237 & 174,0 & 3,10 & 168,6 & 0,97 \\
\hline 5 & 15 & 0 & $0 / 12$ & 9,0 & 6,0 & 15 & 10,50 & 593,8 & 72,2 & 180 & 145,0 & 3,10 & 157,6 & 1,09 \\
\hline & & & & & & & & & & & \multirow{2}{*}{\multicolumn{2}{|c|}{$\begin{array}{l}\text { C. A. and } \\
\text { C. P. }\end{array}$}} & Average & 0,93 \\
\hline & & & & & & & & & & & & & S. D. & 0,11 \\
\hline & & & & & & & & & & & \multirow{2}{*}{\multicolumn{2}{|c|}{ Only C. P. }} & Average & 0,99 \\
\hline & & & & & & & & & & & & & S. D. & 0,07 \\
\hline
\end{tabular}

$\mathrm{n}_{\mathrm{s}}$ - number of steel bars; $\mathrm{n}_{\mathrm{p}}$ - number of strands; $\mathrm{p}$ - spiral transverse reinforcement pitch; $\mathrm{C}$. A. - Reinforced Concrete, C. P. Prestressed Concrete, S. D. - Standard Deviation. 
forces. It reports that for a geometric rate of longitudinal reinforcement greater than the minimum used in the test (12 of $12 \mathrm{~mm}$ diameter bars), the values obtained from the tests are almost all larger than those calculated. However, this is due to the absence, in the expression proposed, of a correlation with the reinforcement ratio, unlike the expression proposed to $V_{c}$ by Merta [28]. The influence of the distance between the applied load and the support is also shown by [27], also resulting in larger values than those calculated by the model proposed. The prestressed concrete beams have very similar results compared to the model used, with an average of 0.99 (ratio between model and test for shear load), the same for the reinforced concrete beams without stirrups and low reinforcement ratio (diameter $12 \mathrm{~mm}$ ). Thus, the model proposed here showed good agreement for the assays discussed here, and is, above all, a good indication for the value of $V_{c}$ (Table 2).

The values for the minimum transversal reinforcement $A_{s w, \min }=\rho_{s w} 100 b_{w} \mathrm{~cm}^{2} / \mathrm{m}$ are adopted according to [15] wherein the geometric rate is $\rho_{s w}=0,2 f_{c t, m} / f_{y w k}$, and $b_{w}$, in the case the thickness of the rib vary with time, is taken as the average width along the height such that $b_{w}=A_{c} /\left(2 r_{\text {ext }}\right)=\pi r_{m} t /\left(r_{m}+t / 2\right)$. By the form of the annular section, two stirrups are used, one for each side, resulting in a 4-legged stirrup. Regarding the maximum spacing between the stirrups can be used in theory, up to a maximum spacing (or $20 \mathrm{~cm}$ or $30 \mathrm{~cm}$, depending on the relationship between $V_{d}$ and $0.67 V_{R d 2}$ ), due to the height $d=0.8 h$.

In any event, the shear represents no impediment in designing the tower due to the large area of the sections. Often, the shear calculation does not reach even the value of $V_{c}$ even without considering the prestressing. As for the active transverse reinforcement, required to join the pre-cast rings that can be divided into up to 3 segments [29], it is not considered here, so each ring is treated as monolithic.

\section{Comparative costs}

\subsection{Parameterization}

As for the geometry adopted, it is made a generalization that also cover frustoconical towers. The bottom half will have parabolic variation to the outer radius and the upper half will be linear. To ensure the continuity of external form, the derivative of the parabola function in the middle of the tower will have the same slope of the linear function which defines the top half. Thus, the towers with frustoconical form are a particular case of the parabolic base towers. The thickness variation may be linear, bilinear and constant because the generation of the geometries is only met the following condition, with $t$ ranging from 5 by $5 \mathrm{~cm}$ :

$20 \mathrm{~cm} \leq t_{\text {top }} \leq t_{\text {mid }} \leq t_{\text {base }} \leq 45 \mathrm{~cm}$

The limits of thickness variation are usual values for both concrete structures and for wind towers ([3] [1], [6], [15] and [2]). The variation of outer radius (about 25 by $25 \mathrm{~cm}$ ) in the middle of the tower will be limited by the following condition, which allows it to also become a frustoconical tower:

$$
r_{\text {ext }, \text { top }} \leq r_{\text {ext,mid }} \leq\left(\frac{r_{\text {ext }, \text { base }}+r_{\text {ext }, \text { top }}}{2}\right)
$$

The outer radius of the base will have a maximum value equal to the outer radius of the top, $182.9 \mathrm{~cm}$ and a maximum of $600 \mathrm{~cm}$ ([6] and [2]). The outer radius of the top is kept constant, with a value equal to that [3], since it is not intended to modify the metallic adapter ring that connects the turbine and tower or the turbine itself.

The frustoconical towers are also investigated separately, by adopting a discretization in ten values, because it allows a variation of less than $50 \mathrm{~cm}$ for the radius in the example used:

$$
v_{\text {ext }, \text { base }}=\frac{r_{\text {ext }, \text { max }}-r_{\text {ext } \text { min }}}{n_{\text {rext }, \text { base }}-1}=\frac{600-182,9}{10-1}=
$$

$$
\frac{417,1}{9} \cong 46,34 \mathrm{~cm}
$$

The same thickness is used for the base, middle and top, making constant thickness along the tower. The value of the thickness variation is $5 \mathrm{~cm}$ considering:

$$
20 \mathrm{~cm} \leq t \leq 45 \mathrm{~cm}
$$

Only for the frustoconical towers is removed the restriction of the natural frequencies of the towers, allowing $f_{1}>1,1 P$. Thus, it is possible to measure the differences in obtaining active and pas-

\begin{tabular}{|c|c|c|c|c|c|c|c|c|}
\hline 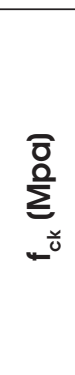 & 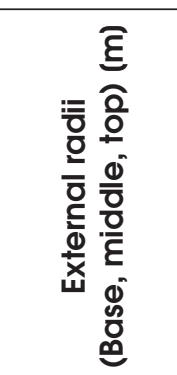 & 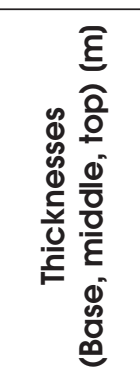 & 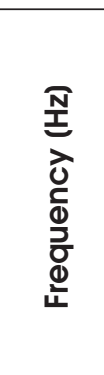 & 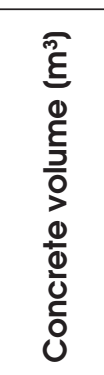 & 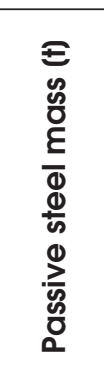 & 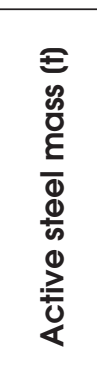 & 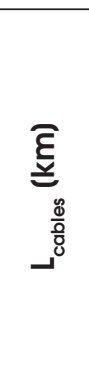 & 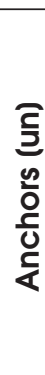 \\
\hline 50 & \multirow{2}{*}{$\begin{array}{c}(5,76,3,79, \\
1,83)\end{array}$} & \multirow{2}{*}{$\begin{array}{c}(0,2,0,2 \\
0,2)\end{array}$} & 0,480 & 474,4 & 12,24 & 16,89 & 2,45 & 64 \\
\hline 180 & & & 0,632 & 475,5 & - & 14,95 & 2,45 & 64 \\
\hline \multicolumn{4}{|c|}{ Ratio (UHPFRC/C50) } & 1,002 & - & 0,885 & 1 & 1 \\
\hline
\end{tabular}
sive reinforcement in relation to the thickness and external radii

\section{Table 3}

Same geometry towers of UHPFRC and C50 
adopted, so that the designs are not prevented for several towers.

\subsection{Material cost}

The comparison between different designs should include overall cost which covers the ease and flexibility in the purchase of materials, the cost of materials, services, transportation and assembly [30]. Certainly implies great difficulty a complete approach about the cost of a tower implantation and, because of this, will be adopted here only the cost of material as a parameter to compare the design. Are considered the values provided by the table of the Sistema Nacional de Pesquisa de Custos e Índices da Construção Civil SINAPI [31] for the state of São Paulo, including the pumping service, arranging them in Table 3. The other values were obtained from the magazine Construção Mercado PINI [32] also for the state of São Paulo. That way:

Concrete Class $\left(\mathrm{R} \$ / \mathrm{m}^{3}\right)$ : C50 $(275,76)$

- Passive Reinforcement $(\mathrm{R} \$ / \mathrm{kg})$ : CA-50 $(4,12)$. Average value adopted for all rebar diameters CA-50;

- Active Reinforcement: CP-190-RB 12,7 (R\$/t 5240,35); Sheath (21,72 R\$/m); Anchor for $12.7 \mathrm{~mm}$ diameter (427,14 R\$/un).

The cost per cubic meter of UHPFRC below which the price would be competitive for the same, is obtained, in this work, equaling the material cost of the towers dimensioned with UHPFRC regarding lower cost tower to C50 class. This is possible since the cost per cubic meter of UHPFRC is the only unknown in the same equation. Disregarding, in a first analysis, only the restrictions placed on the natural frequency of the tower, it is concluded that lower volume towers tend to be more economical towers. This is, in part, confirmed by the often adoption of minimum longitudinal and transverse passive reinforcement throughout the tower and that are related to the geometrical parameters of the section. However, this is, without doubt, the restriction of the maximum displacement permitted in service (L/400).

It is explained because it first meets the form of design adopted, since when used a full prestressing level, the passive reinforcement obtained from ELU verification tends to have a reduced steel

\section{Total cost: frustoconical towers (C50)}
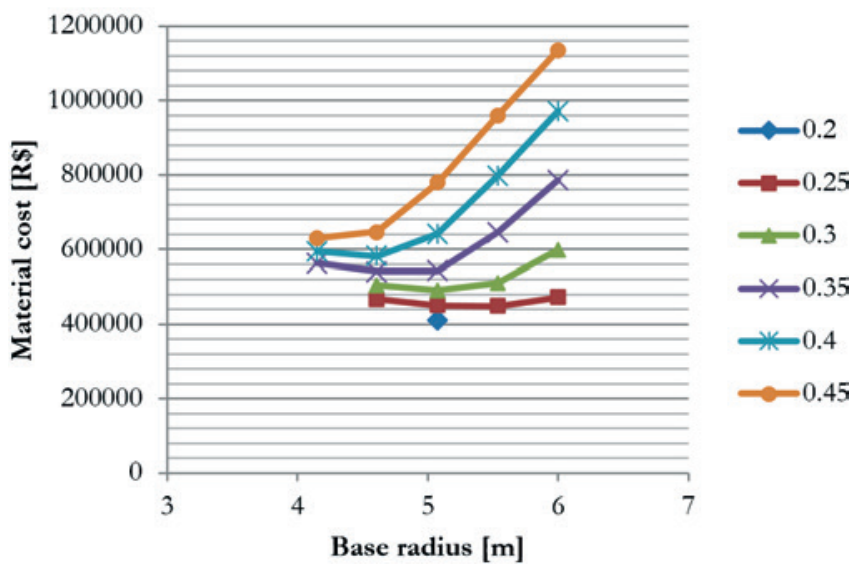

\section{Figure 7}

Total cost of frustoconical towers (C50) for each thickness and restriction $\Delta_{\max }=\mathrm{L} / 250$ area and, often, adopted equal to the minimum, with geometric rate proportional to the concrete area, going to receive even greater contribution of steel passive cost. On the other hand, the smaller the area of concrete sections of the tower, the more flexible it becomes and a bigger active steel area is obtained through design, bearing in mind the geometric nonlinearity and the discrete model, leading to an increase in total material cost of the tower. This situation is not obtained by $\Delta_{\max }=L / 400$, since this displacement limitation at the top of the tower in service prevents their design. However, it is possible to obtain this situation by reducing the limitation of the displacement, for example, to $\Delta_{\text {max }}=L / 250$, varying the distance from the base to the same thickness. Thus, it is evident the turning point of the total material cost relative to the base radius for a certain proportion of thickness or a constant thickness (Figure 7). Figure 8 shows the composition of the total cost for a given thickness for the towers.

Note that, when comparing a tower of same geometry (Table 3), increase in secant stiffness and mass with UHPFRC compared to conventional concrete (C50), reduces the area of the active reinforcement, but not so significant (especially in material cost), therefore, are not reduced, significantly, the internal forces in the structure for the same geometry. However the area of passive reinforcement is reduced to zero.

With $\Delta_{\text {max }}=L / 250$, the most economical C50 class tower is one with parabolic base (Table 4). Regarding this, UHPFRC costs per cubic meter were calculated from the towers analyzed so that its use is competitive referring to this lower cost tower. Also for UHPFRC, the more competitive tower would be a parabolic base (lower volume, less active steel area and without passive reinforcement). However, in this case, the cost per cubic meter was obtained too low to restrictions made (although 2.02 times the cost per cubic meter of $\mathrm{C} 50$, as seen in Figure 7), indicating that under the same conditions loading used herein, the differential may be in tower's geometry (radius and thickness) which cannot be met with conventional concrete, as well as the costs of maintaining, much lower for UHPFRC due to the high durability.

Consideration of fatigue and more severe restrictions on the

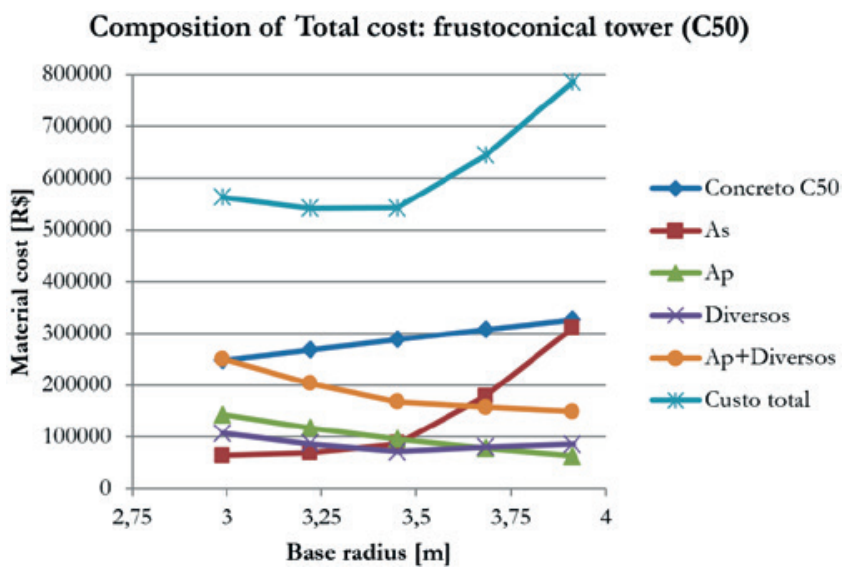

\section{Figure 8}

Composition of the total cost for frustoconical towers (C50) of constant thickness $(35 \mathrm{~cm})$ and restriction $\Delta_{\max }=\mathrm{L} / 250$ 


\section{Table 4}

Low cost towers of UHPFRC and C50

\begin{tabular}{|c|c|c|c|c|c|c|c|c|}
\hline$\underset{\leftarrow}{\sum_{-}^{\circ}}$ & 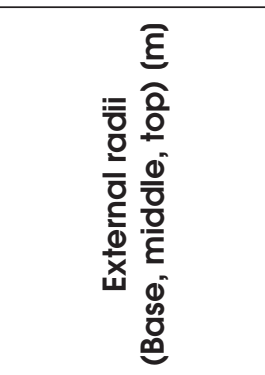 & 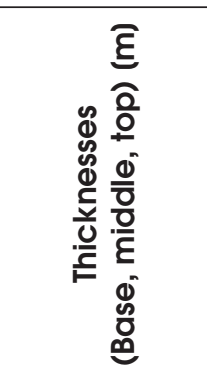 & 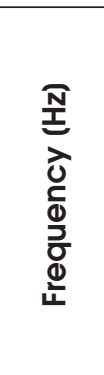 & 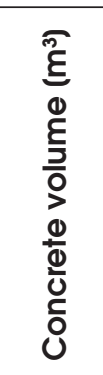 & 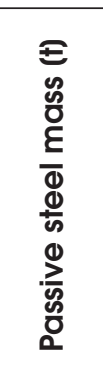 & 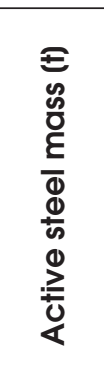 & 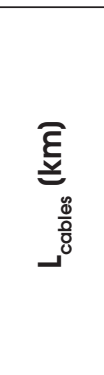 & 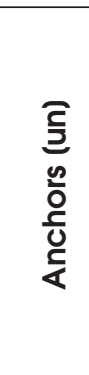 \\
\hline 50 & $(5,76,3,30,1,83)$ & $(0,2,0,2,0,2)$ & 0,419 & 432,5 & 11,06 & 18,36 & 2,40 & 60 \\
\hline 180 & $(6,2,66,1,83)$ & $(0,2,0,2,0,2)$ & 0,442 & 383,6 & - & 17,06 & 2,75 & 64 \\
\hline \multicolumn{4}{|c|}{ Ratio (UHPFRC/C50) } & 0,887 & - & 0,929 & 1,146 & 1,067 \\
\hline
\end{tabular}

possible range of natural frequencies of the tower (rotor operating frequency range) could also change the price per cubic meter of UHPFRC, increasing its competitiveness. It remains to be take into account that the shear at the top of the tower in the ELU (thrust on the rotor) is lower than that in service. Otherwise, there would be a greater possibility of the occurrence of greater reinforcement than the minimum, increasing thus the total cost and enabling a price for greater cubic meter for UHPFRC.

\section{Conclusions}

The growing demand for wind power is driving the development of capacity turbines increasingly on ever higher towers, demanding new solutions in the structural context. This paper discusses various aspects of the structural design of towers for wind power generation made of conventional concrete $\mathrm{C} 50$ class or UHPFRC. The specifications in Brazilian standards and requirements of IEC were

Ratio beetwen UHPFRC competitive costs and C50 cost

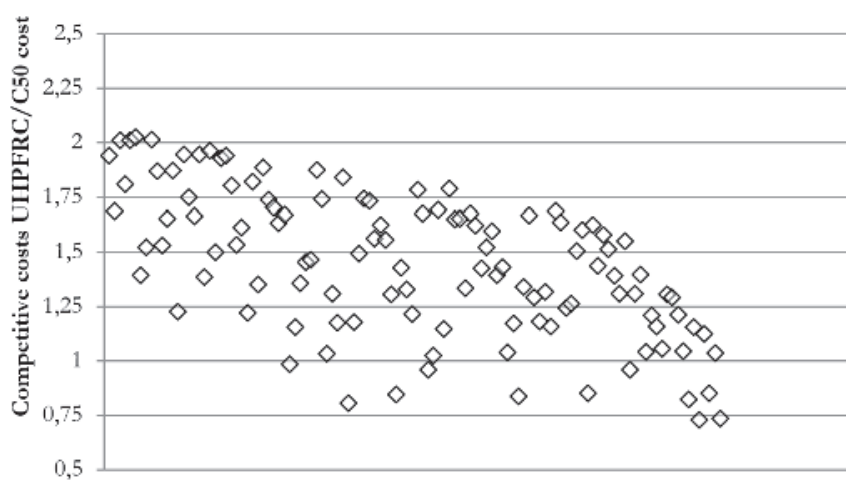

\section{Figure 9}

Relationship between UHPFRC competitive costs and the cost per cubic meter of C50 of several wind towers on the $y$ axis. The $x$-axis refers to the numbering of the tower by design order (that remains implicit numbering) adopted, as well as the interim recommendations of the AFGC. The main results are displayed below:

1. The shear strength obtained by the proposed model agrees with experimental results in the literature, especially regarding the prestressing;

2. A non-linear design model was presented for prestressed slender columns, the group that owns the prestressed concrete wind towers and presented several notes and considerations in the calculation process;

3. Within the restrictions made and considered loads, were obtained for the UHPFRC a value 2.02 times the price per cubic meter to C50 class. Although low, this is only an initial and conservative value, since this study did not discuss issues related to the long-term durability, fatigue and was still maintained to this concrete, the same minimum thickness of others, for the parametric analysis;

4. The limitation of displacement is required, but if excessive, it leads to an increase in stiffness and restricts the design of towers to lower frequencies and therefore deserves further study.

\section{Acknowledgments}

Thanks to CAPES - Coordenação de Aperfeiçoamento de Pessoal de Nível Superior - for partial funding of this research by granting the author masters scholarship.

\section{Bibliographic references}

[1] GRÜNBERG, J.; GÖHLMANN, J. Concrete Structures for Wind Turbines. Berlin: Ernst \& Sohn, 2013. 242 p.

[2] MA, H. W.; MENG, R. Optimization design of prestressed concrete wind-turbine tower. Science China: Technological Sciences. Vol. 57, n. 2, 2014, p. 414-422.

[3] LA NIER, M. P. LWST Phase I Project Conceptual Design Study: Evaluation of Design and Construction Approaches for Economical Hybrid Steel/Concrete Wind Turbine Towers. Golden: National Renewable Energy Laboratory, 2005. 698 p.

[4] CAVALCANTI, M.; CARVALHO, C.; BORBA, A.; CAVALCANTI, A.; ANDRADE, T.; HELENE, P. Qualidade do concreto do 
Parque Eólico de Casa Nova. Concreto \& Construções, Vol. 75, pp. 62-68, 2014.

[5] AFGC - ASSOCIATION FRAINÇAISE DU GÉNIE CIVIL. Bétons fibrés à ultra-hautes performances: Recommandations provisoires. SETRA - Service d'études techniques des routes et autoroutes, France, Janvier, 2002, 152 p.

[6] JAMMES, F. X. Design of Wind Turbines with Ultra-High Performance Concrete. Master thesis, Massachusetts Institute of Technology, Cambridge, 2009. 73 p.

[7] IEC - INTERNATIONAL ELECTROTECHNICAL COMMISSION. Wind Turbines Part 1: Design Requirements. EN 61400-1. $3^{\text {rd }}$ edition, Geneva, 2005.

[8] MALCOLM, D. J.; HANSEN, A. C. WindPACT Turbine Rotor Design Study. National Renewable Energy Laboratory, Colorado, April, 2002. 84 p.

[9] ASSOCIAÇÃO BRASILEIRA DE NORMAS TÉCNICAS. Forças devido ao vento em edificações. NBR 6123. Rio de Janeiro, 1988.

[10] HAU, E. Wind Turbines: Fundamentals, Technologies, Application, Economics. 2nd ed. Berlin: Springer, 2006.

[11] DEUTSCH INSTITUT FÜR NORMUNG. Einwirkungen auf Tragwerke - Teil 4: Windlasten. DIN 1055-4. Berlin, 2005.

[12] CSI. Analysis Reference Manual: For SAP $2000 \AA$, ETABS $®$ and SAFE $®$. Computers and Structures Inc., Berkeley, California, United States, 2009.

[13] ASSOCIAÇÃO BRASILEIRA DE NORMAS TÉCNICAS. Ações e Segurança nas Estruturas - Procedimento. NBR 8681. Rio de Janeiro, 2003.

[14] AMERICAN CONCRETE INSTITUTE. Building Code Requirements for Structural Concrete (ACI 318M-14) and Commentary (ACI 318RM-14). ACI 318. Farmington Hills, 2014.

[15] ASSOCIAÇÃO BRASILEIRA DE NORMAS TÉCNICAS. Projeto de Estruturas de Concreto - Procedimento. NBR 6118. Rio de Janeiro, 2014.

[16] FRANÇA, R. L. S. Contribuição ao estudo dos efeitos de segunda ordem em pilares de concreto armado. Tese de Doutorado, Escola Politécnica da Universidade de São Paulo, São Paulo, 1991. 228 p.

[17] ARAÚJO, J. M. Curso de concreto armado: Volume 3. $2^{\mathrm{a}} \mathrm{ed}$. Rio Grande: Dunas, 2003. 184 p.

[18] SPASOJEVIĆ, A. Structural Implications of Ultra-High Performance Fibre-Reinforced Concrete in Bridge Design. Doctoral thesis Nr. 4051, École Polytechnique Fédérale de Lausanne, Lausanne, Switzerland, 2008.

[19] JUNGWIRTH, J. Zum Tragverhalten Von Zugbeanspruchten Bauteilen Aus Ultra-Holchleistungs-Faserbeton. Doctoral thesis Nr. 3429, École Polytechnique Fédérale de Lausanne, Lausanne, Switzerland, 2006.

[20] CEB-FIP - COMITÉ EURO-INTERNATIONAL DU BÉTON. Model Code for Concrete Structures. 3rd edition, Lausanne, 1978.

[21] CHOLFE, L.; BONILHA, L. Concreto Protendido: teoria e prática. São Paulo: Pini, 2013.

[22] ARAÚJO, J. M. Pilares esbeltos de concreto armado: Parte 1: Um método não linear para análise e dimensionamento. Teoria e Prática na Engenharia Civil, n. 18, Novembro, 2011. p. 81-93.

[23] TEIXEIRA, P. W. G. N.; C. E. M., MAFFEI; M. C. GUAZELLI. Resistência à força cortante de vigas de concreto armado com seção transversal circular. Revista Ibracon de Estruturas e Materiais, Vol. 5, n. 6, Dezembro, 2012, p.781-797.

[24] TURMO, J.; RAMOS, G.; A PARICIO, A. C. Shear truss analogy for concrete members of solid and hollow circular cross section. Engineering Structures 31, 2009, p. 455-465.

[25] ASSOCIAÇÃO BRASILEIRA DE NORMAS TÉCNICAS. Projeto de estruturas de aço e de estruturas mistas de aço e concreto de edifícios. NBR 8800. Rio de Janeiro, 2008.

[26] MERTA, I.; KOLBITSCH, A. Shear area of reinforced concrete circular cross-section members. $31^{\text {st }}$ Conference on OUR WORLD IN CONCRETE \& STRUCTURES: 16-17 August 2006, Singapore.

[27] VÖLGYI, I.; WINDISCH, A.; FARKAS, G. Resistance of reinforced concrete members with hollow circular cross-sections under combined bending and shear - Part I: experimental investigation. Structural Concrete 15, n. 1, 2014.

[28] MERTA, I. Shear strength model of reinforced concrete circular cross-section members. Structural Engineering Mechanics and Computation 3, A. Zingoni, ed. 2007, Seção 22, p. 493-494.

[29] CONCRETE CENTRE. Concrete Wind Towers: Concrete Solutions for Offshore and Onshore Wind Farms. The Concrete Centre (website: www.concretecentre.com), 2005.

[30] DUARTE, E. P. Evolução das torres eólicas pré-moldadas protendidas. Concreto \& Construções, Vol. 75, pp. 36-41, 2014.

[31] SINAPI - SISTEMA NACIONAL DE PESQUISA DE CUSTOS E ÍNDICES DA CONSTRUÇÃO CIVIL. Caixa Econômica Federal, Dezembro, 2014.

[32] PINI. Construção Mercado: Negócio de Incorporação e Construção. São Paulo, n. 163, Fevereiro, 2015. 